\section{Caring for the young athlete: past, present and future}

\author{
Neeru Jayanthi, ${ }^{1,2}$ Joel Brenner ${ }^{3,4}$
}

Caring for the young athlete presents many unique challenges. While there is a growing body of research on the needs of elite level athletes, there is still relatively little evidence or specific recommendations addressing the concerns of the young athlete. By numbers alone, most sports medicine professionals actually care for the millions of young athletes, rather than the smaller proportion of university, professional or Olympic athletes.

The American Medical Society for Sports Medicine (AMSSM) is honoured to contribute to this special issue to provide evidencebased and expert perspectives on the specific needs and concerns relating to younger athletes.

\section{WHAT'S SO 'SPECIAL' ABOUT KIDS PLAYING SPORTS?}

A previous longitudinal cohort study of 453 elite young British athletes outlined the positive benefits of sport, while identifying a knowledge gap of when coaches, parents and athletes should initiate intensive training or specialisation in a single sport. ${ }^{1}$

Recently, multiple organisations have published general recommendations on youth sports training and sports specialisation, recommending against early singlesport specialisation until middle to late adolescence. ${ }^{2-4}$ However, these guidelines have not been sport-specific with regard to age and volume of training. Additionally, several publications have outlined the potential risks of injury and serious overuse injury with higher degrees of sports specialisation while accounting for age and the weekly volume of training. ${ }^{5} 6$ Long-term health consequences related to sports specialisation and intensive training in young athletes have been suggested but have not been adequately demonstrated. On the basis of emerging data regarding short-term injury risk and psychological burnout, the greatest risk of intensive training and early sports specialisation actually may be the marginalisation of children who become

\footnotetext{
${ }^{1}$ Emory Sports Medicine Center, Atlanta, Georgia, USA; ${ }^{2}$ Department of Orthopaedic Surgery, Family Medicine, Emory University School of Medicine, Atlanta, Georgia, USA; ${ }^{3}$ Eastern Virginia Medical School, Norfolk, Virginia, USA; ${ }^{4}$ Children's Hospital of The King's Daughters, Norfolk Virginia, USA

Correspondence to Dr Neeru Jayanthi, Emory Johns Creek Hospital, 6335 Hospital Parkway, Suite 302, Johns Creek, GA 30097, USA;

neeru.jayanthi@emory.edu
}

disengaged from physical activity altogether. $^{2-6}$ An estimated $70 \%$ of children may drop out of organised sport by 13 years of age, particularly young girls. ${ }^{7}$

DiFiori et al explore an innovative model from the NBA on youth player development providing age-specific training guidelines (see page 142). Evans et al present a systematic review of psychosocial experiences for the young athlete that supports lower rates of depression with regular weekly sports involvement, except with highly intense training (see page 169). While player development is an important goal in youth sports, a larger role of sports medicine providers may be to increase physical activity in all children. Joy et al discuss innovative ways to increase awareness of physical activity in children with the use of a 'physical activity vital sign' in paediatric office visits (see page 143).

\section{A 'RISKY PROPOSITION'?}

When a young athlete decides to participate in organised sports, the intent of a preparticipation evaluation (PPE) is to identify the potential risks of participation. However, in the current format, there is insufficient evidence that the PPE reduces future morbidity or mortality. Labotz et al suggest that more innovative PPEs may potentially include targeted medical or sport-specific risk screening or be geared towards performance enhancement (see page 151). The cardiovascular evaluation is one of the most controversial areas in the PPE, and the recommendations regarding preparticipation ECG screening have been under great debate. In a position statement, AMSSM presents evidence-based recommendations regarding cardiovascular screening of athletes (see page 153).

Although individual risk stratification for musculoskeletal injury has been questioned, ${ }^{8}$ integration of injury prevention programmes in young athletes is critically important. Indeed, neuromuscular training for ACL injury prevention in adolescent female soccer players is considered level A evidence. ${ }^{9}$ As suggested by Labella and Meyer, all children should develop basic movement principles termed integrated neuromuscular training (INT) that serve as the foundation for future injury prevention (see page 145). Watson et al describe innovative methods to evaluate subjective well-being and training load as predictors of risk in youth soccer players (see page 194). A novel approach to cumulative risk evaluation of bone health in adolescent male athletes is also presented (see page 200).

\section{INJURY TREATMENT}

Khodaee et al describe injury patterns in boys and girls high school soccer players during a 9-year period with over 3 million athletic exposures demonstrating a significant increase in reported concussions rates (see page 185). Halstead et al also discuss 'brain rest' and the difficulty in determining appropriate return to aerobic activity following concussion (see page 147). A systematic review by Micheo et al informs management recommendations for shoulder instability in athletes younger than 14 years of age (see page 177).

We invite you to attend the AMSSM Annual Meeting (8-13 May 2017-San Diego, California, USA) to explore and discuss additional areas to advance the care of young athletes.

Twitter Follow Neeru Jayanthi @neerujayanthi

Competing interests None declared.

Provenance and peer review Commissioned; internally peer reviewed.

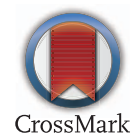

To cite Jayanthi N, Brenner J. Br J Sports Med 2017; 51:141.

Accepted 1 December 2016

Br J Sports Med 2017:51:141.

doi:10.1136/bjsports-2016-097326

\section{REFERENCES}

1 Maffulli N, King J, Helms P. Training in elite young athletes (the training of young athletes (TOYA) study: injuries, flexibility and isometric strength. $\mathrm{Br} /$ Sports Med 1994;28:123-36.

2 LaPrade RF, Agel J, Baker J, et al. AOSSM early sports specialization consensus statement. Orthop I Sports Med 2016;4:2325967116644241.

3 Difiori JP, Benjamin HJ, Brenner JS, et al. Overuse injuries and burnout in youth sports: a position statement from the American Medical Society for Sports Medicine. Br J Sports Med 2014;48:287-8.

4 Brenner JS, Council on Sports Medicine and Fitness. Sports specialization and intensive training in young athletes. Pediatrics 2016;138:pii: e20162148.

5 Jayanthi NA, LaBella C, Fischer D, et al. Sports specialized intensive training and the risk of injury in young athletes: a clinical case-control study. Am J Sports Med 2015;43:794-801.

6 Bell DR, Post EG, Trigsted SM, et al. Prevalence of sport specialization in high school athletics a 1-year observational study. Am J Sports Med 2016;44:1469-74.

7 O'Sullivan J. Changing the game. New York: Morgan James Publishing, 2013.

8 Bahr R. Why screening tests to predict injury do not work - and probably never will...: a critical review. Br J Sports Med 2016;50:776-80.

9 LaBella CR, Hennrikus W, Hewett TE, Council on Sports Medicine and Fitness, and Section on Orthopaedics. Anterior cruciate ligament injuries: diagnosis, treatment, and prevention. Pediatrics 2014;133:e1437-50. 